\title{
A response to an article entitled "Improving teacher professional development for online and blended learning: a systematic meta-aggregative review"
}

\author{
Yunjo $\mathrm{An}^{1}{ }^{10}$
}

Accepted: 3 October 2020 / Published online: 26 October 2020

(c) Association for Educational Communications and Technology 2020

\begin{abstract}
This response reviews the article entitled "Improving teacher professional development for online and blended learning: a systematic meta-aggregative review" (Philipsen in Educ Technol Res Dev 67:1145-1174, 2019) from a practice perspective. Philipsen (Educ Technol Res Dev 67:1145-1174, 2019) conducted a systematic meta-aggregative review that targets teacher professional development for online and blended learning. This paper summarizes the key findings of their study and discusses the value of the findings and how they could be applied to prepare K-12 teachers for online and blended learning. Limitations of the study and suggestions for future research are also discussed.
\end{abstract}

Keywords Blended learning · COVID-19 · Online learning · Professional development programs $\cdot$ Teacher professional development $\cdot$ Teacher training

\section{Summary of the original manuscript}

Philipsen et al. (2019) conducted a systematic review of 15 articles on teacher professional development (PD) for online and blended learning (OBL). The research question that guided the study was: Which components are important for a teacher PD strategy that targets OBL, and why are they important? Using a meta-aggregative approach to qualitative evidence synthesis (Hannes and Lockwood 2011; Joanna Briggs Institute 2014; Lockwood et al. 2015), Philipsen et al. (2019) identified the following six synthesized findings:

(1) Design and develop a supportive teacher PD program and environment for OBL.

(2) Acknowledge the existing context regarding OBL.

(3) Address teacher change associated with the transition to OBL.

(4) Determine the overall goals and relevance of teacher PD for OBL.

(5) Acknowledge teacher PD strategies associated with the transition to OBL.

(6) Disseminate knowledge, skills, and attitudes about OBL and evaluate the teacher PD.

Yunjo An

Yunjo.An@unt.edu

1 University of North Texas, 3940 N Elm St., Denton, TX 76207, USA 
In addition, Philipsen et al. (2019) offered specific suggestions for future teacher PD for OBL by formulating action recommendations based on the six synthesized findings.

\section{Impact/value}

While many existing studies on teacher PD examined general PD approaches, a relatively small number of studies focused on teacher PD for OBL. Further, few studies examined the potential differences between generalized teacher PD and teacher PD for OBL. Philipsen et al. (2019) addressed this gap by conducting a systematic review that targeted teacher PD for OBL. The use of a meta-aggregative approach enabled the authors to provide strong qualitative evidence, identify patterns across the literature, and construct synthesized findings.

The findings of the study provide useful ideas and guidance for preparing K-12 teachers for OBL. As the framework of the key components of teacher PD for OBL illustrates, teacher PD for OBL is not a simple, linear process. Rather, it is a complex process that is influenced by multiple, interrelated components. The framework suggests taking all the different components into account when designing and developing teacher PD for OBL. PD providers should keep in mind that those different components identified in the study are interrelated with each other.

\section{Application}

The unprecedented COVID-19 pandemic has forced K-12 schools and universities to move to online or blended learning. However, many teachers are inexperienced with OBL, and the need for teacher PD for OBL is apparent. Online teaching is quite different from classroom teaching. Being a good teacher in a face-to-face environment does not automatically guarantee effective online teaching. In addition, the transition to online learning often entails psychological changes related to teachers' professional identities and educational beliefs (Wang et al. 2010). As Philipsen et al. (2019) suggest, PD programs should provide teachers with opportunities to reexamine their professional roles and identities (Synthesized finding 3), promote their confidence and motivation in using OBL, and allow them to experience OBL in active and authentic ways (e.g., hands-on experience, real-life applications) (Synthesized finding 5).

The COVID-19 pandemic has exposed the digital divide and educational inequities. The literature reveals that many students do not have reliable Internet access and technology devices needed for online learning (Clausen et al. 2020; Ferdig et al. 2020; Hall et al. 2020). Also, teachers in some school districts do not have adequate devices and tools for online teaching, while other school districts provide teachers with all technology devices and training opportunities. Thus, it is apparent that the "one size fits all" approach will not work since different school districts and different teachers have different needs. As Philipsen et al. (2019) suggest, it is critical to understand teachers' local contexts and needs and provide customized and relevant PD training (Synthesized findings 2 and 4).

The COVID-19 pandemic has forced teachers to step out of their comfort zone and get ready for online teaching within a short timeline. The importance of ongoing support for teacher PD cannot be overemphasized especially in these uncertain and unprecedented times. PD programs should provide a supportive environment with regular and 
just-in-time support and feedback (Synthesized finding 1). A community of teachers and peer support can be used to better support teachers in their PD (Synthesized finding 5). Enabling teachers to disseminate their knowledge, skills, and attitudes about OBL within their schools and communities is another way to support their colleagues' learning and teaching (Synthesized finding 6) (Philipsen et al. 2019).

\section{Limitations}

It is worth noting that Philipsen et al. (2019) used only one database, the ISI Web of Science, and that the findings of the study were from 15 research articles (2004-2015). Future studies should integrate more databases and include more recent studies in order to expand the study. Also, the study focused only on qualitative data. Future research should consider synthesizing both quantitative and qualitative findings to develop a more comprehensive framework of teacher PD for OBL. Although the framework includes many important components of teacher PD for OBL, it does not address content-related components.

\section{Suggestions for future work}

In order to teach effectively in online environments, teachers should acquire new knowledge and skills related to online pedagogy, online communication and interactions, course management systems, online assessments, technology integration, accessibility, copyright compliance, and so on. However, most PD efforts during the COVID-19 pandemic seem to focus on technology training (e.g., how to use a specific online learning platform). Although knowing how to use online learning platforms and tools is very critical for effective online teaching, technology training alone is not enough. The current framework developed by Philipsen et al. (2019) does not address the content aspect of OBL. More research is needed to build a common understanding of the essential knowledge, skills, and competences for online teaching and to elaborate and expand the framework.

\section{Conclusion}

Philipsen et al. (2019) identified six synthesized findings on teacher PD for OBL through a systematic review. The synthesized findings of their study provide useful insights into how to prepare K-12 teachers for OBL. However, the current framework does not address what should be covered in teacher PD for OBL. More research is needed to expand the current framework.

\section{Compliance with ethical standards}

Conflict of interest The author declares that she has no conflict of interest. 


\section{References}

Clausen, J. M., Bunte, B., \& Robertson, E. T. (2020). Professional development to improve communication and reduce the homework gap in grades 7-12 during COVID-19 transition to remote learning. Journal of Technology and Teacher Education, 28(2), 443-451.

Ferdig, R. E., Baumgartner, E., Hartshorne, R., Kaplan-Rakowski, R., \& Mouza, C. (2020). Teaching, technology, and teacher education during the COVID-19 pandemic: Stories from the field. Waynesville: Association for the Advancement of Computing in Education (AACE).

Hall, J., Roman, C., Jovel-Arias, C., \& Young, C. (2020). Pre-service teachers examine digital equity amidst schools' COVID-19 responses. Journal of Technology and Teacher Education, 28(2), 435-442.

Hannes, K., \& Lockwood, C. (2011). Pragmatism as the philosophical foundation for the Joanna Briggs meta-aggregative approach to qualitative evidence synthesis. Journal of Advanced Nursing, 67(7), 1632-1642. https://doi.org/10.1111/j.1365-2648.2011.05636.x.

Joanna Briggs Institute. (2014). The Joanna Briggs Institute reviewers' manual: 2014 edition/supplement. The Joanna Briggs Institute.

Lockwood, C., Munn, Z., \& Porrit, K. (2015). Qualitative research synthesis: Methodological guidance for systematic reviewers utilizing meta-aggregation. International Journal of Evidence Based Healthcare, 13(3), 179-187. https://doi.org/10.1097/XEB.0000000000000062.

Philipsen, B., Tondeur, J., Roblin, N. P., Vanslambrouck, S., \& Zhu, C. (2019). Improving teacher professional development for online and blended learning: A systematic meta-aggregative review. Educational Technology Research and Development, 67, 1145-1174. https://doi.org/10.1007/s11423-01909645-8.

Wang, Y., Chen, N.-S., \& Levy, M. (2010). Teacher training in a synchronous cyber face-to-face classroom: Characterizing and supporting the online teachers' learning process. Computer Assisted Language Learning, 23(4), 277-293. https://doi.org/10.1080/09588221.2010.493523.

Publisher's Note Springer Nature remains neutral with regard to jurisdictional claims in published maps and institutional affiliations.

Yunjo An is an Associate Professor and Chair in the Department of Learning Technologies in the College of Information at the University of North Texas. She received her Ph.D. in Instructional Systems Technology from Indiana University Bloomington. Her research interests include digital game-based learning, gamification of learning, online learning, learner-centered technology integration, teacher professional development, and scaffolding ill-structured problem solving. 